\section{Case Reports in Ophthalmology}

Case Rep Ophthalmol 2018;9:179-184

DOI: $10.1159 / 000487228$

Published online: IVarch 2, 2018

(C) 2018 The Author(s)

Published by S. Karger AG, Basel

www.karger.com/cop

This article is licensed under the Creative Commons Attribution-NonCommercial 4.0 International License (CC BY-NC) (http://www.karger.com/Services/OpenAccessLicense). Usage and distribution for commercial purposes requires written permission.

\title{
Intraocular Lens Dislocation after Cataract Surgery in Tambolaka, Southwest Sumba, Indonesia: A Case Report
}

\author{
Ratna Sitompul \\ Department of Ophthalmology, Faculty of Medicine, Universitas Indonesia, \\ Jakarta, Indonesia
}

\section{Keywords}

Cataract · Surgery · Intraocular lens · Dislocation · Underdeveloped region · Indonesia

\begin{abstract}
Intraocular lens (IOL) dislocation is a rare complication of cataract extraction requiring prompt surgery. This case report aims to raise awareness of such cases and the importance of post-surgery follow-up. A 58-year-old female patient was found with anterior IOL dislocation a week after phacoemulsification surgery in her right eye. Visual acuity of the right eye was $1 / 60$ with ciliary injection and IOL dislocation to the anterior chamber of the right eye. The patient underwent surgery of the right eye and the IOL haptic was found to be broken. In this case report, the factors affecting IOL dislocation are axis length, broken IOL haptic, and patient activity that increased intraocular pressure. Cataract extraction surgery, although common, needs to be conducted carefully, and it is important for ophthalmologists and general practitioners to detect this condition, especially in rural areas where facilities are limited, as IOL dislocation could occur and requires immediate treatment to achieve a better result.
\end{abstract}




\section{Introduction}

Cataract is an opacification of the eye lens due to protein denaturation of the lens. Generally, cataract occurs in the older population (above 55 years old), but several types of it can also be found in children. Cataract is the leading cause of blindness in Indonesia, with an incidence rate of $0.1 \%$ each year [1]. The definitive treatment of cataract is surgery, with an excellent cure rate; however, this bears the risk of complications during and after surgery.

One of the complications of cataract surgery is intraocular lens (IOL) dislocation. Although rare, it will affect patients' quality life, worsening their visual acuity and adding cost to the treatment [2]. This could be monitored by follow-up after surgery. However, follow-up seems to be ignored these days and is not being done properly. Congdon et al. [3] revealed that the follow-up rate after cataract surgery in developed countries is only $20-30 \%$.

This case report discusses anterior IOL dislocation (ICD-10 H27.121) of the right eye 1 week after cataract surgery. The aim of this report is to raise ophthalmologists' awareness to perform cataract extraction delicately and of general practitioners to conduct postsurgery follow-up.

\section{Case Presentation}

A 58-year-old female patient from Tambolaka, Southwest Sumba, Indonesia presented for a follow-up after mass cataract extraction surgery. She graduated from high school and lives as a farmer. Before undergoing mass cataract extraction surgery, she complained of blurred vision in both eyes for 1 year. Upon examination, best visual acuity after correction was $1 / 300$ for the right eye and $1 / 60$ for the left eye. There was no history of other ocular disease prior to surgery. The patient was diagnosed with bilateral mature senile cataract. She then underwent phacoemulsification surgery of her right eye on August 27, 2016 in a mass cataract surgery in the hospital using a regular foldable lens. One week after the surgical procedure, the patient came to the hospital for post-surgery checkup and complained of sudden blurred vision in her right eye. History of eye trauma was denied by the patient. She admitted that before the symptoms appeared, she had often carried heavy loads around 5$10 \mathrm{~kg}$ and drawn water from wells as her daily activities. Upon physical examination, blood pressure was $130 / 90 \mathrm{~mm} \mathrm{Hg}$ and visual acuity of the affected right eye was $1 / 60$. Ciliary injection was found in the right eye along with IOL in the anterior chamber (Fig. 1). Another surgery was later performed on the patient to replace the dislocated IOL with a new one. During the second operation, the trailing haptic was found to be broken. Post-surgery visual acuity of the right eye was $6 / 21$.

\section{Discussion}

IOL dislocation is one of complications after cataract surgery that may occur after a few days to months. The incidence of IOL dislocation within the first week after operation is 0.2$2.8 \%$ [4]. Anterior IOL dislocation was found on 1 out of 110 patients that were operated, with no previous data of anterior IOL dislocation being reported in Indonesia.

There are few risk factors of IOL dislocation, such as short axial length of the eye, uveitis, diabetes mellitus, trauma, older age, and eye rubbing [5]. Other factors that play a role are 


\section{Case Reports in Ophthalmology}

Case Rep Ophthalmol 2018;9:179-184

DOI: $10.1159 / 000487228$

C 2018 The Author(s). Published by S. Karger AG, Basel www.karger.com/cop

Sitompul: Intraocular Lens Dislocation after Cataract Surgery in Tambolaka, Southwest Sumba, Indonesia: A Case Report

the type of surgery, the design and material of the IOL, capsule contraction, intraoperative haptic defect, and severe myopia [2, 6, 7].

Deshmukh et al. [8] stated that an intraoperative haptic defect can occur when using a foldable IOL, especially during folding and implantation of the IOL. Before being implanted, the IOL is put inside an injector. The operator must perform lens insertion carefully and slowly as the IOL haptic could be broken and thus lead to unstable fixation. If the IOL is unstable, it can easily be displaced into the sulcus, where the normal fibrotic process of attaching the lens to the capsular bag does not occur. This will lead to displacement of the IOL into the anterior chamber. In this particular case, the IOL may have been displaced when implanted, in addition to the broken trailing haptic, thus causing the anterior IOL displacement.

Kang et al. [9] stated that there are few factors causing haptic defect, one of them being compression due to activities involving an increase in intraocular pressure. Activities such as lifting of heavy objects could increase intraocular pressure and push the IOL and IOL haptic anteriorly, hence the defect of the IOL haptic. Klysik et al. [10] stated that axial length and low IOL power could be the risk factors of lens dislocation within 5 years of surgery and that the axial length is statistically significant in the incidence of IOL dislocation $(p=0.009)$. Longer axial length also contributes to a higher risk of IOL dislocation.

In our case, there were few risk factors that played a role in the incidence of IOL dislocation. The surgeon and nurses were competent and had a lot of experience in operating cataract patients. Therefore, it was unlikely that the surgeon made a fatal mistake in the procedure, even though other factors, such as time of operation and fatigue of the operator, may also have influenced the result of the operation. In this particular case, the patient was the sixth patient that was operated on that day, and the operation was done late at night in the setting of mass cataract surgery in a rural hospital. These factors could have caused an error in the procedure, resulting in breaking and displacing of the IOL. In this case, the operator also ensured that the IOL was placed behind the iris before the patient left the operating theater.

The IOL haptic, especially the trailing haptic, can be damaged intraoperatively due to incorrect placement of the injector, hence the IOL may not be placed right into the capsular bag and may thus have a higher chance of being displaced anteriorly. A defect in the IOL haptic can increase the risk of the IOL slipping out of the capsular bag, hence placing it on the sulcus where fibrotic tissue cannot be formed and the IOL is not locked in place, leading to dislocation of the IOL. In our case, it is believed that this was the mechanism of IOL dislocation. The quality of the IOL may play a role in the result of the surgery. The lens used was a regular foldable lens, which has been proven inferior compared to premium foldable lenses; however, as the context of the surgery was one of mass cataract surgery in a rural area, the regular foldable lens was the only kind of lens available.

Another possible reason might have been the lifting of heavy objects after surgery. When the patient lifts heavy objects, intraocular pressure will increase and may push the IOL into the anterior chamber. Other possible explanation is axial length; however, measurement of axial length was not performed, thus we are unable to draw a conclusion.

The Indonesian Ophthalmologist Association has given out guidelines for patients before and after surgery. There are a few things that should be paid attention to, such as control time, changing of drapes, no water contact for 1 week, no coughing, no lifting of objects weighing $>5 \mathrm{~kg}$, no smoking, and no eye rubbing for 3 weeks. In this case, the patient was given the necessary information, but did not adhere to it as she had to take water from the well, wash clothes, and bring home the wet clothes by putting them on top of her head. This practice may have increased intraocular pressure, hence causing dislocation. 
Mass cataract surgery in this case was carried out as part of a community service by a team of ophthalmologists from Jakarta. The event was carried out between July 11 and 17, 2016 in a hospital in Southwest Sumba. The personnel of this event included 5 ophthalmologists, 2 refractionists, 3 ophthalmology residents, and 4 medical students. All of the medical staffs participating in the mass surgery were competent and experienced. Before the event, patients were examined for visual acuity, anterior eye chamber, posterior chamber, intraocular pressure, blood pressure, and blood glucose. From the examination, 110 patients were scheduled to undergo surgery. Patients were monitored for 1 day after surgery, and all doctors ensured that there were no complications. No mydriatic drops were prescribed after the surgery.

One week after surgery, the patient presented for a follow-up examination and IOL dislocation was found. However, to fly doctors and equipments from Jakarta was not simple and could not be carried out instantly. On the other hand, surgery was immediately required and if not performed might affect the patient's vision permanently. Hence, the patient was referred to a hospital in Bali where she underwent another surgery. The surgery went well despite the extra cost of transportation and accommodation of the referral to Bali for 1 week.

When conducting cataract surgery in rural areas where human resources and facilities are limited, complications must be monitored carefully and if possible must be prevented. Thus, ophthalmologists should carry out the procedure and monitoring carefully. The prevention of such cases should start intraoperatively, with the surgeon paying close attention to carefully putting the foldable IOL inside the injector. It should be ensured that the IOL is attached to the capsular bag successfully, promoting the normal fibrotic process that stabilizes the lens. It is preferable that ophthalmologists stay in the region for 1 week after surgery or that ophthalmologists and their equipments can be flown in immediately should there be any complications. General practitioners and ophthalmology-trained nurses should be trained to detect complications, carry out early treatment, as well as refer and accompany patients in case of complications. Education should also be given to patients and next of kin as to what is allowed and not allowed after surgery with regards to their socioeconomic status. To those in rural areas, education should be given using simple local language they understand, as the correct delivery of information could prevent complications.

\section{Conclusion}

This study is the first to report anterior IOL dislocation in Indonesia. IOL dislocation can occur within days to months after cataract extraction surgery. A broken haptic can move the IOL from its designated placement site, hence the dislocation. Thus, education of patients and their family is vital before and after surgery with regards to their socioeconomic status and local culture. This complication can occur even in the hands of skilled ophthalmologists, but can easily be repaired when detected early. Active participation of general practitioners and nurses in rural areas is required to follow up and detect these complications early after cataract extraction surgery. This case report also reminds every ophthalmologist to perform cataract extraction surgery carefully, especially in rural areas where facilities are limited. 


\section{Acknowledgements}

The author would like to thank the chief of the village, the head of the district health office, and the head of the Southwest Sumba district for their support during the study. She would also like to thank A.A.G. Oka Wiryanatha, MD, the director of the hospital where the surgery took place, for his continued support.

\section{Statement of Ethics}

Ethical approval was obtained from the ethics committee of the Faculty of Medicine, Universitas Indonesia (clearance number 877/UN2.F1/ETIK/2016, protocol number 16281).

\section{Disclosure Statement}

The author declares no conflict of interest.

\section{References}

1 Pusat Data dan Informasi Kementrian Kesehatan RI: Situasi Gangguan Penglihatan dan Kebutaan. Jakarta Selatan, 2014.

2 Shah MA, Shah SM, Mehta R, Shah P: Spontaneous dislocation of lens bag with acrylic lens after uneventful cataract surgery - unusual complication of cataract surgery. GMS Ophthalmol Cases 2015;5:Doc11.

-3 Congdon N, Yan X, Lansingh V, Sisay A, Müller A, Chan V, Jin L, Meltzer ME, Karumanchi SM, Guan C, Vuong Q, Rivera N, McCleod-Omawale J, He M: Assessment of cataract surgical outcomes in settings where follow-up is poor: PRECOG, a multicentre observational study. Lancet Glob Health 2013;1:e37e45.

-4 Kloda KD, Kloda T, Boudiaf S, Jakobsson G, Stenevi U: Incidence and risk factors of late in-the-bag intraocular lens dislocation: evaluation of 140 eyes between 1992 and 2012. J Cataract Refract Surg 2015;41:1376-1382.

-5 Ascaso FJ, Huerva V, Grzybowski A: Epidemiology, etiology, and prevention of late IOL-capsular bag complex dislocation: review of the literature. J Ophthalmol 2015;2015:805706.

-6 Krepste L, Kuzmiene L, Miliauskas A, Januleviciene I: Possible predisposing factors or late intraocular lens dislocation after routine cataract surgery. Medicina (Kaunas) 2013;49:229-234.

-7 Fernández-Buenaga R, Alio JL, Pérez-Ardoy AL, Larrosa-Quesada A, Pinilla-Cortés L, Barraquer R, Alio JL 2nd, Muñoz-Negrete FJ: Late in-the-bag intraocular lens dislocation requiring explantation: risk factors and outcomes. Eye (Lond) 2013;27:795-802.

8 Deshmukh RR, Gatzioufas Z, Bessant D: Broken intraocular lens haptic: an interesting outcome: a case report. Adv Opthalmol Vis Sys 2016;5:145-146.

-9 Kang H, Han KE, Kim TI, Kim EK: Spontaneous fracture of an implanted posterior chamber polyimide intraocular lens haptic: a case report. Indian J Ophthalmol 2014;62:348-350.

10 Klysik A, Bartkowiak KK, Jurowski P: Axial length of the eyeball is important in secondary dislocation of the intraocular lens, capsular bag, and capsular tension ring complex. J Ophthalmol 2016;2016: 6431438. 
Sitompul: Intraocular Lens Dislocation after Cataract Surgery in Tambolaka, Southwest Sumba, Indonesia: A Case Report

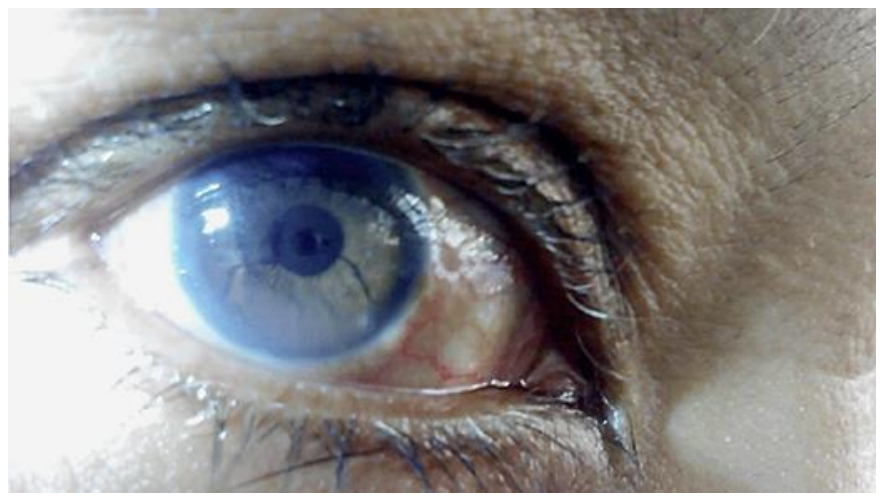

Fig. 1. One week after phacoemulsification surgery in the right eye. There was ciliary injection, but the cornea was clear. The intraocular lens is seen in the anterior chamber of the eye. The chamber was still noticeably deep and the pupil was within normal limits. 